\title{
The Risk Analysis of Geological Disaster Based On GIS
}

\author{
Yifei Xing \\ College of Geoscience \&Surveying Engineering, China University of Mining and Technology, \\ Beijing 100083, China
}

hunter2011@foxmail.com

Keywords: Geological Disaster; Risk Analysis; GIS

\begin{abstract}
Risk analysis of geological disasters is a new field appears in recent year which attracts more and more people's attention. Geological disaster risk refers to geological disasters and their possible damage losses on human activities. In this paper, the definition and concept of geological disaster risk elements are analyzed, the application of GIS in geological disaster risk analysis systems, hazard zoning system, regional evaluation forecasting and early warning technology are discussed, noting that the applications of GIS technology in geological disaster risk analysis process is the inevitably means in analysis and evaluation of geological disasters risk in the future.
\end{abstract}

\section{Introduction}

Geological disaster refers to people's lives and property caused by geological hazard or geological phenomenon. Geological disasters belong to an important hazard of natural disasters, which not only brings to threaten human survival and development, but also for the environment, resources, property, etc. destructive. Now, with the increasing human activities, its size and strength, the contradictions between human beings and the environment has intensified, resulting in the frequency of geological disasters is increasing, the impact of increasing the scope of the harm caused more serious. In some areas, geological disasters have become an important factor restricting the impact and social and economic development.

Geographic Information Systems (GIS) are effective expression, processing and analysis and geographic distribution of technical expertise related data, which provide people with a quick display of geographic information and analysis of information about the new tools and platforms. Core GIS is the spatial data management subsystem, the spatial data processing and spatial data analysis composition. GIS with data acquisition and extraction, conversion and editing, data integration, reconstruction and conversion data, query and retrieval, and analysis of space operation, space and data display outputs and outcomes and other updated features. 48th Meeting of the Asia-Pacific Economic and Social (Economic and Social Commission for Asia and Pacific) in April 1992 held in Beijing pointed out: "The meeting held that RS and GIS technology has become the environmental monitoring, mitigation of natural disasters, management of natural resources and make Its essential tool for sustained development and become interdisciplinary application technology. " China in the United Nations with the help formulate "China's Agenda 21", including 63 priority areas of development, including 40 involved in the construction of information systems and applications of remote sensing technology. Visible, GIS technology has become the human survival, progress, development of a closely related science and technology of information.

\section{The Connotation of GIS}

GIS (Geographic Information System) is a computer hardware and software support to the collection, storage, management, retrieval, analysis and description of the space object positioning and attribute data associated with them, and answer user questions as the main computer system tasks. Also, the geographic information system has the following characteristics: (1) geographic information systems analysis and processing problems in the use of spatial data and attribute data, and through the database management system linked to the two co-management, analysis and application, thus providing awareness A new way of thinking geographic phenomena. (2) 
Geographic Information Systems emphasizes spatial analysis, through the use of spatial analytic model to analyze the successful application of spatial data and geographic information system depends on the spatial analysis model and design research. The successful application (3) Geographic information system depends not only on technical system, but also on certain organizational system (including the implementation of the composition, system administrators, technical operators, systems development designers, etc.). (4) Although the IT for the development of geographic information systems play an important role. However, the practice has proved that the human factor increasingly important influence in the development of geographic information systems, many of the applications of geographic information system has been beyond the scope of art.

\section{The Concept and Composition of Geological Disaster Risk}

The concept of geological disaster risk has a variety of different interpretations. In a study of UNESCO's program, Varnes (1984) suggested that the risk of natural disasters and definitions of terms, and subsequently has been widely recognized by the international research in the field of geological disasters, become geological hazard, vulnerability and the basic model of risk assessment. The risk of geological disasters defined as: within a certain time limit areas, the phenomenon of loss of specific geological hazards to life, property, economic activity may cause. It can be expressed as

$$
R=f(H, E, V)
$$

Equation (1) can be further expressed as

$R=H \times E \times V$

Where: R (Risk) risk of geological disasters, referring to the loss of a particular phenomenon may cause geological disasters; $\mathrm{H}$ (Hazard) is the probability of a certain area of an underlying phenomenon of geological disasters occur within a certain period of time, namely, the risk of geological disasters; E (Element) to be subject to a specific threat of geological disasters in a given area of the object, including population, property, infrastructure, economic activities; V (Vulnerability) for specific geological disasters occur with a certain intensity and the extent of loss caused by the threat of an object, namely the vulnerability of the threatened objects, it is represented by 0 to 1 ( 0 for no loss, 1 for total loss). As can be seen, the risk of geological disasters $(\mathrm{H})$ and threatened objects (E) vulnerability $(\mathrm{V})$ together determine the magnitude of the loss of geological disasters, is the basic condition to control geological disasters risk (R), and for two analysis and evaluation of those referred to geological hazard assessment and socio-economic vulnerability assessment.

\section{The Geological Disaster Risk Analysis System Based on GIS Technology}

As one of the core technology of Digital Earth, GIS technology provides a new way to learn knowledge and understanding of information, it has been widely used in land resources survey, environmental quality assessment, regional planning, public facilities management. In the field of geological disasters, from the initial application of GIS technology, data management, multi-source data acquisition and digital input and output graphics to use digital elevation models, digital terrain model, GIS combined with extended analysis hazard assessment models, GIS and decision-making support system integration, GIS applications of virtual reality technology, and gradually develop and in-depth applications.

Geological disasters occurred in the earth's surface within a certain time and a certain spatial range limits, although different types of geological disasters, between different individuals of the same kind of geological disasters mostly shapes, forming mechanism is vastly different, but they are breeding environment and disaster trigger factor interaction results, and these are closely related to spatial information, GIS technology can not only take advantage of a variety of geological disasters and related information management, but also from different spatial and temporal scales on statistical analysis of the relationship between environmental factors between geological disasters, geological disasters evaluation of the probability of occurrence and the possible consequences of a 
disaster.

GIS as management can not only like a traditional database management system (DBMS) numbers and text (attribute) information, but also to manage space (graphic) information; it can use various methods of spatial analysis, information on a variety of different integrated analysis, to find the relationship between spatial entities, analyze and process phenomena and processes within a regional distribution. Forward contemporary GIS can provide a rich, comprehensive spatial analysis capabilities of GIS intelligent direction. Intelligent GIS has strong spatial modeling capabilities to build a variety of professional, comprehensive and integrated analysis of geoscience model to accomplish specific practical work to solve previously only by experts in order to solve problems.

General GIS software platforms provide some basic spatial analysis tools, such as regional overlay analysis, buffer analysis, vector and raster data conversion, attribute data query retrieval, digital elevation models, digital terrestrial simulation analysis, but only the direct use of these basic risk analysis tools of geological disasters is clearly unrealistic, which requires a combination of the specific situation in the basic GIS platform developed with a variety of professional geoscience model of combining analysis module, such as information model, the expert can score model, artificial neural network models and basic GIS platform combines risk analysis applied to geological disasters in.

After years of research, the development of geological disaster risk analysis system RiskAnly based on commercial GIS software. The system is excellent domestic GIS software MAPGIS 6.0-based platform for development, combined with a variety of professional geo-science analysis model and we can achieve a variety of different types of geological disasters (such as landslides, mudslides, karst collapse, etc.) for risk analysis, easy loss analysis and the final risk assessment. System to analyze the actual work needed to guide the design, according to the basic properties of geological disasters, combined with the characteristics of GIS software, modular program design.

Geological disaster risk analysis system using GIS technology (RiskAnly) based on the realization of a better combination of GIS technology and geological disaster risk analysis model, GIS can take full advantage of the graphical editor, property management, spatial analysis, digital elevation analysis and other functional advantages, fast facilitate the realization of the general analysis methods and means to solve difficult problems. It can be changed according to the situation and the information, is the potential of geological disaster risk analysis, risk analysis and further reduce ambiguity and uncertainty, with strong accuracy and objectivity) which is the means of conventional analytical incomparable.

\section{The Applications of GIS Technology in Geological Risk Hazard Analysis}

The Application of GIS in Geological Disaster Risk Analysis System. GIS technology to build their own intelligent integration features "professional" comprehensive and can be applied in practical work geo-science model to change the status quo of traditional entirely on expert analyzed and summarized in solving the problem. Especially not the same formation mechanism of geological disasters Geological disasters or individuals, can use GIS technology management-related information and analysis of geological disasters and its influencing factors statistical relationship at different spatial scales or different time scales, as a basis for the probability of the possible consequences of the disaster to make a reasonable assessment.

The Application of GIS in geological hazard zoning system. Zoning model based on GIS technology system mainly refers to the next level to evaluate the risk of geological disasters or developmental level of the application system, it is the main tool to study geologic hazard regionalization and government departments to develop mitigation decisions in obtaining "information storage and processing spatial data with great respect the advantages in terms of geological disasters zoning, GIS-based application system is mainly composed of many individuals under such a degree of danger to predict or evaluate "the development trend of forecast" risk evaluation model is composed using the concept of hierarchy previously mentioned acquisition can the results reflect the forecast of geological disasters laws. 
The Application Analysis of GIS in Regional evaluation of geological disaster forecasting and warning. Geological disaster system based on GIS technology in the monitoring and early warning capabilities have. In the monitoring information system, its main set of four system image "management" applications and data management in one, and other monitoring information storage and management. In the early-warning system, its external damage to the slope such as engineering cumulative impact of rain as the basis, the outbreak of the area to make the analysis of geological disasters, thus achieve regional early warning and forecasting.

\section{Conclusion}

The application of GIS technology in geological disasters risk analysis process is the inevitable means in the future analysis and evaluation of geological risk disasters. In the actual application process we should pay attention to analyze its principle, and consider the characteristics and history of the dangers and potential dangers of different regions and other geological disasters. At the same time we need to give full play to the advantages of GIS technology in risk analysis, risk monitoring and risk zoning and early warning, in order to reduce the impact of geological disaster on human production activities.

\section{References}

[1] Y.K. Long, The Landslide Hazard Zoning and GIS Application. Earth Science Frontiers, 2001,8 (2): 279-2830.

[2] S. Fang,. GIS and Geological Environment Evaluation. Geological Hazards and Environment, 2000,11 (1): 6-10.

[3] G.R Zhong, Spatial Analysis (2nd Edition). Wuhan: Wuhan Surveying and Mapping Technology University Press, 2000.

[4] L.F. Zhu, Regional Geological Hazard Information Analysis System Based on GIS Technology. Chinese Journal of Geological Hazard and Control, 2001,12(3): 79-83. 